\title{
Meningiomas of the Craniovertebral Junction: A Review
}

\author{
Michael A Galgano, Timothy Beutler, Aaron Brooking and Eric M Deshaies*
}

Department of Neurosurgery, SUNY Upstate Medical University, Syracuse, NY, USA

\begin{abstract}
Meningiomas are tumors originating from the meninges of the brain and spine that are typically benign. Mass-effect and traction of nearby structures resulting in neurological sequelae often predicates surgical resection. Vital structures are unavoidably encountered en route to craniocervical junction meningiomas, posing a significant surgical challenge. The clinical presentation varies based on neoplasm size and location. Resection techniques also vary based on individual anatomy and the required exposure.
\end{abstract}

\section{Keywords: Meningioma; Neurosurgery; Craniocervical Junction}

\section{Introduction}

Meningiomas are tumors originating from the meninges of the brain and spine that are typically benign; however, there are welldescribed subtypes that have a more aggressive nature, clinically and pathologically. Meningiomas have the potential to be located anywhere from the convexity of the brain to the most distal aspect of the spine. Although meningiomas often are pathologically benign, their ability to situate themselves in locations inhabited by vital central nervous system (CNS) structures often makes them a surgical challenge. In this paper, we will focus on meningiomas that predominate at the craniocervical junction.

\section{Pathology of Meningiomas}

The term meningioma represents a broad histological group of tumors with variable behavior, derived from meningothelial cells that are typically attached to the inner surface of the dura mater, and are classified by the World Health Organization (WHO) grades I, II and III [1]. Meningiomas can arise from any location where meninges or ectopic meninges may exist, and represent nearly one third of all primary intracranial neoplasms and one quarter of all primary spinal cord neoplasms [2]. In children (ages 0-19), the incidence of meningioma is $3.7 \%$ with a male to female ratio of $1: 1$. While $90 \%$ of meningiomas are benign (grade I), the incidence of atypical (grade II) and anaplastic (grade III) are 6-8\% and 2-3\% respectively [3,4].

Cushing described these tumors as arising from meningial origin. This served as a unifying description for a group of histologically and genetically diverse tumors, thought to be derived from arachnoid cap cells. Arachnoid cap cells function as a structural barrier, act as a conduit for cerebrospinal fluid (CSF) resorption, aid in monocytelike functions, participate in reactive gliosis, and aid in detoxification within the CNS $[1,5]$. The meninges comprise the dura mater and the leptomeninges (arachnoid and pia mater). Dura forms an outer endosteal layer related to the bones of the skull and spine and an inner layer closely applied to the arachnoid mater. Leptomeninges have multiple functions and anatomical relationships. The outer parietal layer of arachnoid is impermeable to CSF due to tight intercellular junctions; elsewhere leptomeningeal cells form demosomes and gap junctions. Trabeculae of leptomeninges compartmentalize the subarachnoid space and join the pia to arachnoid mater. In bacterial meningitis leptomeningeal cells secrete cytokines. Pia mater is reflected from the surface of the brain and spinal cord onto arteries and veins, thus separating the subarachnoid space from the brain and cord. A sheath of leptomeninges accompanies arteries into the brain and is related to the pathways for the drainage of interstitial fluid that play a role in inflammatory responses in the brain and appear to be blocked by amyloid-beta in Alzheimer's disease. Specialised leptomeningeal cells in the stroma of the choroid plexus form collagen whorls that become calcified with age. Leptomeningeal cells also form channels in the core and apical cap of arachnoid granulations for the drainage of CSF into venous sinuses. In the spine, leptomeninges form highly perforated intermediate sheets of arachnoid and delicate ligaments that compartmentalize the subarachnoid space; dentate ligaments anchor subpial collagen to the dura mater and stabilize the spinal cord. Despite the multiple anatomical arrangements and physiological functions, leptomeningeal cells retain many histological features that are similar from site to site $[1,5]$. Arachnoid cap cells demonstrate mixed epithelial and mesenchymal origins, appearing normally as a single layer resembling fibroblasts, or epitheliod nests composed of multiple layers. Clustering of arachnoidal cap cells and the concomitant formation of whorles and psammoma bodies become increasingly prominent with age, and are identical with the characteristics of meningiomas. These cytological similarities, and the behavior of the cells, serve as the basis for arachnoid cap cells being favored as the likely cell origin of meningiomas [1].

Loss of heterozygosity of the neurofibromin 2 gene (NF2), located at the 12.2 region on chromosome 22 , is the most common genetic abnormality found in meningiomas, and is responsible for $60 \%$ of sporadic as well as the majority of NF2 associated meningiomas. The NF2 gene codes for the protein Merlin and although its function is poorly understood, is thought to play a role in the 2 hit model of tumor inactivation. Consistent with tumor suppressor gene inactivation theory, up to $60 \%$ of meningiomas have an associated NF2 gene mutation, which potentially serves as the initiating event of tumorigenesis, particularly those demonstrating a mesenchymal phenotype [1]. Tumor suppressor gene DAL- $1 / 4.1 \mathrm{~B}$, located on chromosome 18 , is a member of the 4.1 protein superfamily and is another gene that has commonly been associated with meningiomas. The role of this gene may contribute less to the initiation of tumorigenesis as initially thought, and may serve as a progression locus for sporadic tumors [6]. Alterations of the $1 \mathrm{p}$, $14 \mathrm{q}$, chromosome 10 and $18 \mathrm{q}$ have been associated with atypical and anaplastic grades to a higher degree.

Multiple meningiomas are found in about $1-2 \%$ of patients with an

*Corresponding author: Eric M Deshaies, Department of Neurosurgery, SUNY Upstate Neurovascular Institutel 750 East Adams Street Syracuse, NY 13210 USA, Tel: 315-464-5502; Fax: 315-464-6373; E-mail: deshaiee@upstate.edu

Received November 21, 2013; Accepted December 26, 2013; Published December 31, 2013

Citation: Galgano MA, Beutler T, Brooking A, Deshaies EM (2013) Meningiomas of the Craniovertebral Junction: A Review. J Spine 3: 150. doi:10.4172/21657939.1000150

Copyright: (c) 2013 Galgano MA, et al. This is an open-access article distributed under the terms of the Creative Commons Attribution License, which permits unrestricted use, distribution, and reproduction in any medium, provided the original author and source are credited. 
already known meningioma [7]. This statistic rises in individuals with neurofibromatosis type 2 [8]. There are some reports in the literature that make reference to the fact that some meningiomas may actually spread through the CSF pathways. The majority of these cases described the meningiomas pathologically as malignant or angioblastic [8-12].

\section{Craniovertebral Junction Meningiomas}

\section{Epidemiology}

Approximately 2-3\% of all meningiomas originate at the foramen magnum [13-17]. Meningiomas occur roughly three times more often than schwannomas, which are the second most common benign tumor found at the foramen magnum [18]. Various subtypes of meningiomas have been found in this location, including xanthomatous, clear cell, lymphoplasmacytic-rich, transitional, and meningothelial $[19,20]$.

\section{Clinical presentation}

Patients typically become symptomatic from craniovertebral junction meningiomas between 35 and 60 years of age. Pediatric cases of craniovertebral junction meningiomas are well-described, although not as common as in the adult population. As with meningiomas elsewhere in the brain and spine, females tend to be more often afflicted. In fact, around $66-73 \%$ of craniovertebral junction meningiomas are represented by females [21-23]. Clinically, craniovertebral junction meningiomas present with neurological sequelae resulting from mass effect and traction of nearby structures. They may also cause vascular compromise, hydrocephalus, and syringohydromyelia [15,24]. These lesions are often attached to the anterior ring of the foramen magnum. Frequently they invade the region of the entrance around the vertebral artery and the exit of the cervical roots $[17,20,25]$. They may cause location-specific symptoms based on whether they are predominantly intracranial, extracranial, or a combination.

Craniocervical junction meningiomas most frequently extend above and below the foramen magnum equally, although they can be predominantly intracranial or intraspinal. Intracranial components of the meningioma may cause brainstem dysfunction and lower cranial nerve neuropathies, as well as occasional cerebellar signs. Cranial nerve palsies may be the result of traction, or brainstem nuclear involvement via mass compression [26]. The vagus, glossopharyngeal, and hypoglossal are the most commonly affected cranial nerves. Some patients may describe slurred speech, difficulty swallowing, and recurrent pneumonia, from repeated episodes of aspiration. The dysphagia may lead to unwanted weight loss. High cervical meningiomas produce myelopathic features, and occasionally cause spinal accessory nerve dysfunction with the potential to cause torticollis. They can also cause sensory aberrations to the face from descending trigeminal nerve tracks being affected. In addition, lower decussations of motor and sensory tracks may be affected [26]. So-called "straddle lesions" have a tendency to produce minimal dysfunction to the lower cranial nerves, but predominantly cause a high cervical myelopathy. At the craniocervical junction, there tends to be a rather sizeable area of subarachnoid space that is accommodating to a growing mass. This generally allows these meningiomas to grow to significant sizes before they become symptomatic and discovered. Pain is often the primary complaint. It is often localized to the second cervical dermatome, involving the suboccipital region. The pain often is aggravated by head and neck motion. The patient may actually present with posterior headaches, and a condition resembling torticollis, with the head held in flexion [27].

Some patients with meningiomas, as well as other tumors in this region involving the high cervical spinal cord, may describe an abnormal cold sensation in their lower extremities. This may in fact be pathognomonic of high cervical cord lesions [24,28]. Pain and temperature sensation is often affected, preceding loss of proprioception. Some patients describe a "dissociated" sensory loss, with areas of sensory preservation in the upper extremities. If the sensory decussation of the medial lemniscus is affected, a varied pattern of sensory deficits may be encountered. Painful dysesthesias and paresthesias of the hands, limbs, and face may be encountered. Meningiomas at the foramen magnum may actually produce a combination of long track signs in both the upper and lower extremities. Spastic weakness is common. A distinct pattern of motor involvement is also evident. Typically, motor deficits progress in a "circular" fashion, first affecting the ipsilateral upper extremity, followed by the ipsilateral lower extremity, contralateral lower extremity, and finally the contralateral upper extremity [29]. Localized ipsilateral intrinsic hand muscle weakness and atrophy may develop. One of the proposed mechanisms is decreased venous drainage and subsequent venous stasis of the anterior horn cells. Other theories include CSF obstruction with resultant hydromyelia, spinal cord edema from venous obstruction, anterior spinal artery compression, and rotation of the spinal cord from contralateral traction [30]. On occasion, symptoms such as drop attacks, paralysis, and vertebrobasilar syndromes may arise. These can be from vascular changes or biomechanical craniocervical junction instability [31].

\section{Surgical resection}

The primary goal of treating foramen magnum meningiomas is to preserve and improve neurological function via surgical resection [18]. Magnetic resonance imaging (MRI) provides high-resolution pictures of the tumor and gives important information for surgical planning, such as its relationship to the brainstem and surrounding structures including vital vasculature. Typically, meningiomas are isointense on T1-weighted imaging and isointense to hypointense on T2-weighted imaging. With gadolinium administration, they avidly enhance. Magnetic resonance angiography (MRA) may be used pre-operatively for surgical planning as an alternative to standard angiography. MRA can allow clinicians to assess the patency of the vertebral artery. MRV (magnetic resonance venogram) may also be used to evaluate vital dural venous sinuses that may be in the proposed operative trajectory. Plain $\mathrm{x}$-rays of the craniocervical junction may reveal subtle changes such as calcification or erosion around the foramen magnum. They may also show widening of the interpedicular spaces of upper cervical vertebrae [32].

Craniovertebral junction meningiomas may be situated in the ventral foramen magnum, as well as the posterior foramen magnum. Anteriorly located lesions are certainly a greater surgical challenge. Critical neural structures such as the brainstem, lower cranial nerves, vertebral artery, in addition to the occipital condyle, are a hindrance to exposure of the ventral foramen magnum. Surgical exposure of the ventral foramen magnum typically requires a large and complex posterolateral approach, which also raises the likelihood of subsequent morbidity and mortality given the abovementioned structures that are necessary to navigate around [32]. One of the most frequent complications of surgery on foramen magnum meningiomas are lower cranial nerve palsies. These palsies are quite significant to the patient, because they sometimes necessitate further procedures such as feeding tubes and tracheostomies. This contributes to a longer length of hospital stay, and may contribute to postoperative mortality by increased risk of aspiration pneumonia $[23,33]$. Other post-operative complications include hydrocephalus requiring CSF diversion, meningitis, and CSF leak. Occipital-cervical instability can also occur in the post-op period, 
however, this complication may be avoided by resecting no more than one third to one half of the occipital condyle [32].

Several surgical approaches have been proposed for the removal of craniovertebral junction meningiomas including the stardard midline suboccipital craniotomy and high cervical laminectomy [34-39]. Modified approaches have been developed to forge better outcomes in situations where a standard approach would be difficult. Such approaches include an anterior transoral [40], endonasal transclival [41], lateral transcervical [42], and posterolateral suboccipital approaches [38]. In order to accomplish a complete, but safe resection of meningiomas situated in the ventral foramen magnum, techniques involving partial removal of the occipital condyle in combination with transposition of the vertebral artery, have been established [10,15,17,18,20,29,43-46]. Avoidance of occipital condyle resection and manipulation of vital structures such as the vertebral artery may be accomplished through anterior approaches for ventrally located meningiomas. Some authors have proposed an expanded endonasal transclival approach for anterior craniocervical junction lesions, such as meningiomas [47,48]. A transoral transclival approach has also been described for resection of anterior craniocervical junction meningiomas [40].

\section{Spinal stability}

Attempting to determine specific factors leading to instability, as well as the actual stabilizing structures in the occipital-cervical region, can be challenging and complex. "Clinical stability" is dependent on the spine being able to maintain its pattern of displacement, such that there is no additional neurological deficit, major deformity, or significant incapacitating pain and discomfort [49]. The articular stability between the occiput and $\mathrm{C} 1$ depends on various factors including the cupshaped occipital-atlantal joint configuration, the fibrous capsule of this joint, and the anterior and posterior atlanto-occipital membranes [49]. The tectorial membrane, as well as the alar, cruciate, and apical ligaments, all play additional roles in occipital-atlantal articular stability [49]. It has been postulated by some that less than $70 \%$ removal of the condyle allows adequate occipital-atlantal stability, while greater than $70 \%$ removal often necessitates a stabilizing fusion procedure [50]. This "70\% limit" proposed by Sekhar corresponds to resection beyond the hypoglossal canal and the tubercle, where the alar ligament inserts over the medial aspect of the condyle [50]. A biomechanical study by Vishteh et al., however, showed that removal of greater than $50 \%$ of the condyle produced statistically significant hypermobility at the occipital-C1 junction. They also showed that after a $75 \%$ resection, the biomechanics of the Occiput-C1 and C1-2 motion segments changed considerably [51]. Based on clinical experience and other biomechanical studies, other authors also feel that occipital-cervical fusion be performed when greater than $50 \%$ of the condyle is resected [31].

The extreme lateral transcondylar approach entails removing the condyle either partially or completely. This technique may lead to post-operative instability. One of the factors leading to this instability includes loss of the insertion of the transverse ligament over the lateral mass of $\mathrm{C} 1$. Loss of the insertion of the alar ligament over the occipital condyle also contributes, as does loss of part, or the entire cup-shaped articular surface of the occipital condyle. Lastly, destruction of the fibrous capsule around the occipito-atlantal articulation may also contribute, especially if it is violated posteriorly and laterally, where it is the thickest, and provides the most reinforcement [50]. Stabilization procedures of the occipital-cervical region typically involve a plate/rod system for the occipital bone, with occipital bone screws in the midline keel, $\mathrm{C} 2$ pedicle screws, and lateral mass screw fixation of the sub-axial spine.

\section{Conclusion}

Meningiomas of the craniocervical junction are undoubtedly a fascinating surgical challenge faced by neurosurgeons. Although they are typically pathologically benign, their locations, and the approaches used to access them, pose significant risks to the patient. Diligent pre-operative planning and meticulous surgical technique must be employed to yield the best surgical outcome for the patient.

\section{References}

1. Mawrin C, Perry A (2010) Pathological classification and molecular genetics of meningiomas. J Neurooncol 99: 379-391.

2. Engelhard HH, Villano JL, Porter KR, Stewart AK, Barua M, et al. (2010) Clinica presentation, histology, and treatment in 430 patients with primary tumors of the spinal cord, spinal meninges, or cauda equina. J Neurosurg Spine 13: 67-77.

3. McLendon RE, Rosenblum MK, Bigner DD (2006) Russell and Rubinstein's Pathology of Tumors of the Nervous System. CRC Press.

4. Langford LA (1996) Pathology of meningiomas. J Neurooncol 29: 217-221.

5. Weller RO (2005) Microscopic morphology and histology of the human meninges. Morphologie 89: 22-34.

6. Nunes F, Shen Y, Niida Y, Beauchamp R, Stemmer-Rachamimov AO, et al (2005) Inactivation patterns of NF2 and DAL-1/4.1B (EPB41L3) in sporadic meningioma. Cancer Genet Cytogenet 162: 135-139.

7. Borden NM (1995) Aggressive angioblastic meningioma with multiple sites in the neural axis. AJNR Am J Neuroradiol 16: 793-794.

8. Kamiya K, Inagawa T, Nagasako R (1989) Malignant intraventricular meningioma with spinal metastasis through the cerebrospinal fluid. Surg Neurol 32: $213-218$

9. Ludwin SK, Conley FK (1975) Malignant meningioma metastasizing through the cerebrospinal pathways. J Neurol Neurosurg Psychiatry 38: 136-142.

10. Hoffmann GT, Earle KM (1960) Meningioma with malignant transformation and implantation in the subarachnoid space. J Neurosurg 17: 486-492.

11. Akimura T, Orita T, Hayashida O, Nishizaki T, Fudaba H (1992) Malignan meningioma metastasizing through the cerebrospinal pathway. Acta Neurol Scand 85: 368-371.

12. Kumar PP, Good RR, Skultety FM, Masih AS, McComb RD (1987) Spinal metastases from pituitary hemangiopericytic meningioma. Am J Clin Oncol 10: 422-428.

13. Meyer FB, Ebersold MJ, Reese DF (1984) Benign tumors of the foramen magnum. J Neurosurg 61: 136-142.

14. Menezes $\mathrm{AH}$ (2008) Craniovertebral junction neoplasms in the pediatric population. Childs Nerv Syst 24: 1173-1186.

15. al-Mefty O, Borba LA (1997) Skull base chordomas: a management challenge. J Neurosurg 86: 182-189.

16. Passacantilli E, Santoro A, Pichierri A, Delfini R, Cantore G (2005) Anterolatera approach to the craniocervical junction. J Neurosurg Spine 3: 123-128.

17. Bassiouni H, Ntoukas V, Asgari S, Sandalcioglu El, Stolke D, et al. (2006) Foramen magnum meningiomas: clinical outcome after microsurgical resection via a posterolateral suboccipital retrocondylar approach. Neurosurgery 59 1177-1185; discussion 1185-1187.

18. Al-Mefty O (1998) Operative Atlas for Meningiomas. Lippincott-Raven.

19. Yamaki T, Ikeda T, Sakamoto Y, Ohtaki M, Hashi K (1997) Lymphoplasmacyterich meningioma with clinical resemblance to inflammatory pseudotumor Report of two cases. J Neurosurg 86: 898-904.

20. Castellano F, Ruggiero G (1953) Meningiomas of the posterior fossa. Acta Radiol Suppl 104: 1-177.

21. Howe JR, Taren JA (1973) Foramen magnum tumors. Pitfalls in diagnosis JAMA 225: 1061-1066.

22. Colli B, Al-Mefty O (2001) Chordomas of the craniocervical junction: follow-up review and prognostic factors. J Neurosurg 95: 933-943.

23. Samii M, Klekamp J, Carvalho G (1996) Surgical results for meningiomas of the craniocervical junction. Neurosurgery 39: 1086-1094. 
Citation: Galgano MA, Beutler T, Brooking A, Deshaies EM (2013) Meningiomas of the Craniovertebral Junction: A Review. J Spine 3: 150. doi:10.4172/2165-7939.1000150

Page 4 of 4

24. Beatty RA (1970) Cold dysesthesia: a symptom of extramedullary tumors of the spinal cord. J Neurosurg 33: 75-78.

25. Dodd RL, Ryu MR, Kamnerdsupaphon P, Gibbs IC, Chang SD Jr, et al. (2006) CyberKnife radiosurgery for benign intradural extramedullary spinal tumors. Neurosurgery 58: 674-685.

26. Menezes AH, Traynelis VC, Fenoy AJ, Gantz BJ, Kralik SF, et al. (2005) Honored guest presentation: surgery at the crossroads: craniocervical neoplasms. Clin Neurosurg 52: 218-228.

27. Harsh G, Janecka I (2003) Chordomas and Chondrosarcomas of the Skull Base and Spine. Thieme.

28. Bambakidis NC, Dickman CA (2012) Surgery of the Craniovertebral Junction. Thieme.

29. Cohen L, Macrae D (1962) Tumors in the region of the foramen magnum. $J$ Neurosurg 19: 462-469.

30. Taylor AR, Byrnes DP (1974) Foramen magnum and high cervical cord compression. Brain 97: 473-480.

31. Shin H, Barrenechea IJ, Lesser J, Sen C, Perin NI (2006) Occipitocervical fusion after resection of craniovertebral junction tumors. J Neurosurg Spine 4 : 137-144.

32. Winn HR (2011) Youmans Neurological Surgery. Elsevier Health Sciences.

33. ArnautoviÄ $\ddagger \mathrm{KI}$, Al-Mefty O, Husain M (2000) Ventral foramen magnum meninigiomas. J Neurosurg 92: 71-80

34. Guidetti B, Spallone A (1988) Benign extramedullary tumors of the foramen magnum. Adv Tech Stand Neurosurg 16: 83-120.

35. Love JG, Thelen EP, Dodge HW Jr (1954) Tumors of the foramen magnum. J Int Coll Surg 22: 1-17.

36. Samii PD med M, M.d MA (1992) Meningiomas Involving the Lower Clivus and the Foramen Magnum (Craniospinal Meningiomas) [Internet]; in : Surgery of Skull Base Meningiomas. Springer Berlin Heidelberg.

37. Smolik EA, Sachs E (1954) Tumors of the foramen magnum of spinal origin. $J$ Neurosurg 11: 161-172.

38. Yasargil MG, Mortara RW, Curcic M (1980) Meningiomas of Basal Posterio Cranial Fossa [Internet]; in Krayenbühl H, Brihaye J, Loew F, Logue V, Mingrino $\mathrm{S}$, Pertuiset B, et al. (eds): Advances and Technical Standards in Neurosurgery.
Springer Vienna.

39. Zoltán L (1974) [Tumours at the foramen magnum (author's transl)]. Acta Neurochir (Wien) 30: 217-225.

40. Miller E, Crockard HA (1987) Transoral transclival removal of anteriorly placed meningiomas at the foramen magnum. Neurosurgery 20: 966-968.

41. Kassam AB, Gardner P, Snyderman C, Mintz A, Carrau R (2005) Expanded endonasal approach: fully endoscopic, completely transnasal approach to the middle third of the clivus, petrous bone, middle cranial fossa, and infratempora fossa. Neurosurg Focus 19: E6.

42. Stevenson GC, Stoney RJ, Perkins RK, Adams JE (1966) A transcervical transclival approach to the ventral surface of the brain stem for removal of a clivus chordoma. J Neurosurg 24: 544-551.

43. Charles YP, Barbe B, Beaujeux R, Boujan F, Steib JP (2011) Relevance of the anatomical location of the Adamkiewicz artery in spine surgery. Surg Radiol Anat 33: 3-9.

44. Gamache FW Jr, Wang JC, Deck M, Heise C (2001) Unusual appearance of an en plaque meningioma of the cervical spinal canal. A case report and literature review. Spine (Phila Pa 1976) 26: E87-89.

45. Gottfried ON, Gluf W, Quinones-Hinojosa A, Kan P, Schmidt MH (2003) Spina meningiomas: surgical management and outcome. Neurosurg Focus 14: e2.

46. Hafiz MG, Rahman MR, Yeamin MB (2013) Intradural intramedullary spina cord meningioma in a seven years old female child. Mymensingh Med J 22 180-185.

47. Kassam A, Carrau RL, Snyderman CH, Gardner P, Mintz A (2005) Evolution of reconstructive techniques following endoscopic expanded endonasal approaches. Neurosurg Focus 19: E8.

48. Prevedello DM, Fernandez-Miranda JC, Gardner P, Madhok R, Sigounas D, et al. (2010) The transclival endoscopic endonasal approach (EEA) for prepontine neuroenteric cysts: report of two cases. Acta Neurochir (Wien) 152: 1223-1229.

49. White AA 3rd, Panjabi MM (1987) Update on the evaluation of instability of the lower cervical spine. Instr Course Lect 36: 513-520.

50. Bejjani GK, Sekhar LN, Riedel CJ (2000) Occipitocervical fusion following the extreme lateral transcondylar approach. Surg Neurol 54: 109-115.

51. Vishteh AG, Crawford NR, Melton MS, Spetzler RF, Sonntag VK, et al. (1999) Stability of the craniovertebral junction after unilateral occipital condyle resection: a biomechanical study. J Neurosurg 90: 91-98. 